\title{
Smart Ancient Cities: Towards PAES Compilation. The Case History of Magliano Toscana and Canarias Islands
}

\author{
Fedora Quattrocchi ${ }^{1 *}$, Federico Giannuzzi ${ }^{2,3}$ \\ ${ }^{1}$ INGV: Istituto Nazionale Geofisica e Vulcanologia, Via di Vigna Murata 605, Roma, Italy \\ ${ }^{2}$ Engineering Department, Università di Bologna "Alma Mater", Bologna, Italy \\ ${ }^{3}$ Universidad de Las Palmas de Gran Canaria (ULPGC), Islas Canarias, Canada
}

Corresponding Author Email: fedora.quattrocchi@libero.it

https://doi.org/10.18280/ti-ijes.640109

Received: 18 April 2019

Accepted: 12 June 2019

\section{Keywords:}

PAES-PEC, smart cities and communities, smart ancient cities, low-carbon energy density, Magliano Toscana, Canarias islands, geothermal energy, sustainability

\begin{abstract}
The purpose of the present paper is that to analyze the state of the art of the Territorial Energetic Planning (Piano Energetico Comunale, PEC, including PAES - Piano d'Azione per l'Energia Sostenibile) keeping in mind the various available energy-heat productiontechnologies, with particular reference to those "low carbon", that include the Renewable Energy Sources ones (RESs onward). The roles of the various corporate body are examined departing from the European Energetic Planning, passing for the National Energetic Strategy up to focus on a more specific situation for our ancient country, with the Plan of Action for the Sustainable Energy (PAES) of an ancient city. Besides, evolving the European "Vision" of the classical "Smart Cities and Communities" we are deepening the concept of "Smart Ancient Cities", in the frame of new strategies for the sustainable mobility, the energetic retraining and the diffusion of the Renewable Energetic Sources (RESs) in reworked Ancient Towns, coupling energy efficiency, energy low-carbon production, cultural heritage, smart architectonic restoration by ICT too, anti-seismic strengthening, in a unique resilience path for the single-out selected Ancient Town: Magliano in Toscana (GR) in primis.

The first example of "Smart Ancient Citiy" and "Low Carbon" ancient town, typical of the Italian's panorama, as select example of an ancient suburbs, is the Municipality of Magliano Toscana, that has a Convention of Research with INGV (National Institute of Geophysics and Volcanology), to discuss the Plan of Action for the Sustainable Energy (PAES) as translated: Sustainable Energy Action Plan (SEAP). In this ancient little town an important energetic-architectural retraining has been effected, regarding the various energy-heat supply chains, starting a first gross calculationof the Low Carbon Producible Energy Density as translated into "Energy Density Productive Low Carbon (DEPLC)", producible as [MWhe /hectar/year] and [Mwht/hectar/year], normalized to the $\mathrm{CO}_{2}$ emissions (GHGs onward), from where to starting the future Smart Ancient City development in the frame of HORIZON2020 planning and calls. The real available experimental data have been analyzed for illumination, transports, schools, geothermal energy available or potential in the Municipality, including the Bio-masses/Biomethane Plant locally operative (Luigi Vivarelli Enterprice) and all the most recent evolutions developed by this Municipality for "low-carbon" energy/heat/resources production.

Another example of systems "Smart Ancient Cities" and "Low Carbon" ancient area, introduced in this study, is the Canarias Islands, that thanks to their territorial characteristics and the geographical position on the sea, they can use to the best the anticipated technologies from the European calls HORIZON 2020 "Smart Cities and Communities" with an evolution toward the "Smart Ancient Cities" concept, using RESs of last generation both in the eolic and in the photovoltaic framework. The geothermal potential is rewiewed here. The scientific results in terms of Energetic Density normalized to the GHGs avoided in atmosphere, is compiled by experimental new data, jointed with the pre-existing ones, that include considerations both energetic and economic through the analysis of real estimates, for the installations of the energetic systems, with respect to the monthly and annual production as is furnished by the Municipality, hypothesizing a period of reported amortization to the initial investment. The results and the data of the annual daily irradiation have been gotten and analyzed thanks to the software "The Satellite Application Facility on Climate Monitoring" (CMSAF), made by an EU Project and to the Grafcan founded by the government of Canarias islands, as available.
\end{abstract}

\section{INTRODUCTION}

The most urgent problem of Humanity is to produce a large quantity of energy (9 billion people almost!) by the minimum GreenHouse Gases production (onward GHGs), in the minimum space and time as possible. The GHGs production is 
the main cause of climate change in the world, despite the skepticism: the lighter Carbon isotopic signature of the Northern emisphere with respect to the Southern emisphere of the Earth is enough to demonstrate the human industrial origin of the new-excess GHTs in the atmosphere. Climate change has already resulted in observable and catastrophic consequences for human health as well as the World economy increasingly.

This work, which is part of the HORIZON 2020 "Smart Cities and Communities" calls evolution (Quattrocchi F. as part of the Italian Set Plan Energy enlarged Board, MIUR Ministry), has had the purpose of examining some energy technologies, including renewable ones and their possible applications in Italian territory and not only, starting from typically Italian contexts, that is the ancient villages, with a tourism-vocation, near the sea, but perhaps slightly on an hill, where typically the ancient villages rose for medioeval defensive reasons, deepening from the concept of "Smart Cities and Communities" toward the concept of "Smart Ancient Cities"- All this is focused to exploit new strategies for sustainable mobility, the energetic retraining and the diffusion of the Renewable Energetic Sources (RESs onward), in parallel with the" Unified European Directive for the use of subsurface and lands to produces energy / heat/resources" (see Quattrocchi F. web site http://fedoraquattrocchi.mysupersite.it/ and the AIGE Congress 2019 Proceedings, https://www.aige2019matera.it/ ). The establishment of European calls for proposals such as "Smart Cities and Communities" HORIZON 2020, aim to create a European area of research and development, mobilizing private and public investments in some sectors considered decisive for the competitiveness such as energy and low-carbon transport, waste treatment and public clean water. To participate at European level in the aforementioned calls, there is a mandatory need to have a well-defined energy framework and planning, certificate already in official protocols, for each municipality beforehand; this is identified in the Sustainable Energy Action Plan (SEAP).

The SEAP is an energy planning document, associated with the individual and local administrative entity in its peculiarity, which outlines a data collection profile, energy production activities and performs basic surveys that lead to tangible, experimental measures evolved in the state of the art and really applicable energy policies. The SEAP must clearly indicate the strategic actions that the local authority intends to take to achieve the objectives set for 2020 (HORIZON 2020) [1-7].

\section{METHODS}

As part of a Research Convention between INGV (Fedora Quattrocchi, Scientific Responsible) and the Municipality of Magliano in Toscana, to discuss the Plan of Action for the Sustainable Energy (PAES) - as translated Sustainable Energy Action Plan (SEAP) - real energy experimental data, produced by public and private structures were taken into consideration, as an experimental basis to start some calculations, bearing in mind that the concept of new low-carbon energy encompasses all possible sectors: corporate, private, public and environmental i.e., energy and heat production, possibly normalized to the GHGs avoided in the atmosphere compared to "no low carbon" analogue energy classical production. At the same time, energy technologies were studied and developed in a similar situation, a Smart Ancient City near the sea as well as the Canary Islands, and then a discussion to start a comparison was made for the two sites.

Before doing this, the concepts of PAES and the analysis of the Low Carbon Producible Energy Density [8-10] were translated into "Energy Density Productive Low Carbon (DEPLC)", producible as $\left[\mathrm{MWh}_{\mathrm{e}} /\right.$ hectar/year $]$ and [Mwh/hectar/year] namely considering the space-time variables too, often under-evaluated or "hidden", not only for small and medium-sized enterprises, but also for small towns and ancient villages, with high cultural value and artistic.

The present study refers to data and consumption, coming from various technologies for energy production, which instead of being presented with different physical quantities were normalized to the above mentioned DEPLC variable, with the relative $\mathrm{CO}_{2}$ emissions reduced and therefore avoided in the atmosphere, to be calculated instant by instant in the municipal ICT synoptic system.

In summary, the work was structured as follows:

- the pact of recent years of the Set Plan Energy (Fedora Quattrocchi member of the SPE Enlarged Board, Ministry of the Ministry of Education MIUR) is studied and reworked, its aims and implementation tools with which to achieve them, then defining the National Energy Strategy (SEN) and prospects reach toward a new EU Directive about Energy planning: Unified European Directive for the use of subsurface and lands to produces energy / heat/resources".

- the PAES (in Italian) or SEAP (in English) is critically studied and reworked and the general techniques to be undertaken and the research to be carried out are outlined in order to arrive at a correct technical draft, for the single Municipality.

- a definition is made of the Municipal Energy Plan (PEC) and of the objectives set in the Action Plan for the single municipality.

- one enters more specifically with regard to the interventions and concrete possibilities that can be implemented in the territory of a small municipality like that of Magliano in Toscana, identifying the various operational chains in which to focus by new devices and calculation;

Starting from this experience, the Italian potentials referring to the new concept of "Smart Ancient Cities" have been highlighted, that is to say ancient tourist towns with a growing need and potential for technological, energy and historicalarchitectural restoration, taking the advantage of Herity International partner in writing EU Projects (www.herityinternational.org) to make them live the rest of the year and not just in summer.

Both the sites taken in consideration have geothermal potential, with medium-high enthalpy resources too, and here only hints and a little review is performed. Geothermal energy in the Magliano in Toscana territory was stopped as a consequence of some "geothermal speculation" in the closest regions and the author (Quattrocchi F.) limited here action only to methods of communication strategies for public awareness and public acceptance of geothermal energy (https://sosgeotermia.noblogs.org/tag/fedora-quattrocchi/)

The main objectives concern low-carbon energy productivity and the increase in energy efficiency (i.e., [11]) buildings, municipal infrastructures, large, small and mediumsized industrial plants and public transport, as well as the diffusion of hybrid plants that can help stabilize the network, in parallel with the classic RESs development by simply improving the input data for irradiation, wind speed and heat (i.e., [11-14]). Here is an analysis of two different views taken 
into consideration and the methods used.

\section{1 "Smart Ancient City Magliano in Toscana"}

Given that there are few studies of municipal territorial energy planning in Italy, with particular reference to the synergies and uses of the soil and subsoil (energy storage, gas, $\mathrm{CO}_{2}$ or nuclear waste, geothermal energy, RESs) and considering that these studies and assessments of the territory, carried out by research institutions, encouraging international schools on the topic too (i.e., by INGV: [15-17]) together with Italian universities; in this manner all together we are increasingly in demand for the drafting of European proposals, the degree thesis projects are part of a Research Convention between INGV and the Municipality of Magliano in Toscana, for the formulation of the SEAP and in turn addresses the PEC.

The research is based on a study of the energy density calculation $\left[\mathrm{Mwh}_{\mathrm{e}} /\right.$ hectar/year] including the one that produces heat $\left[\mathrm{Mwh}_{\mathrm{t}} / \mathrm{hectar}_{\mathrm{y}} \mathrm{year}\right]$, normalized to the GHGs avoided in atmosphere [8-10], namely which can be produced with low-carbon technologies, energy efficiency and energy savings, in time and space, for the Municipality of Magliano in Toscana. This strategic use of a unique variable for all the energy production chains and comparable territorial energy planning of lands and subsurface, is prerequisite of a unique comparable planning, region by region (see Quattrocchi F., this volume), being now the planning expressed in different variables, generating a big confusion for the comparison. Using a unique variable for the different Municipalities (6000 in Italy), a "Energy rehabilitation" - typically feasible and desirable in ancient villages such as Magliano in Toscana - is evaluable comparatively, for the different ancient cities; this energy aspect is therefore developed in parallel and superimposed research and development on the artisticarchaeological-cultural and touristic "restructuring", to attract young technologists/engineering as well as handicraft, in search of low-carbon work/job and sustainable tourism, in turn generating new human activities, in a reproducible synergy for all the countless ancient Italian villages (vedi "Patto dei Sindaci (https://www.pattodeisindaci.eu/about-it/lacomunit\%C3\%A0-del-patto/firmatari.html ).

One of the first applications in the territory of Magliano in Toscana is the energy requalification of public structures: the municipality, schools and sports centers. in this perspective the irradiation values and the possible productivity of energy from renewable sources were analyzed.

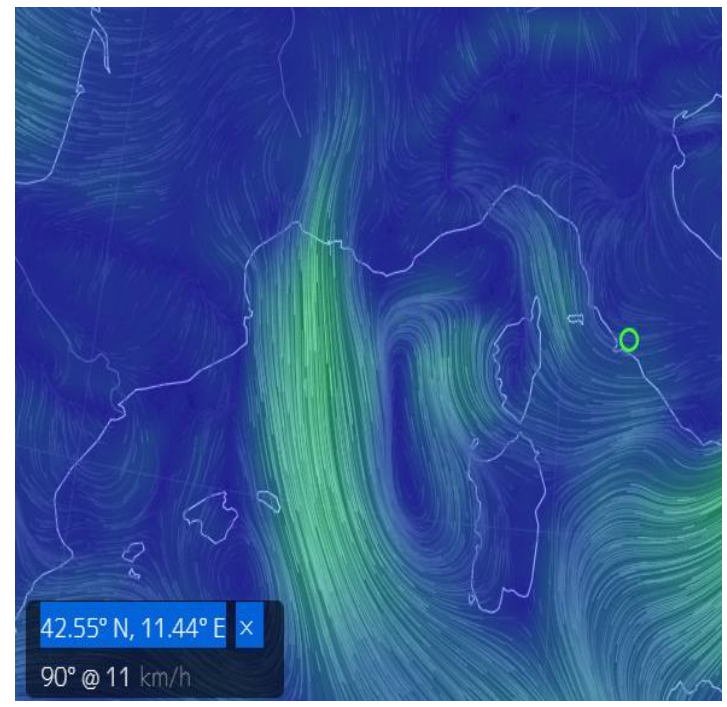

(a)

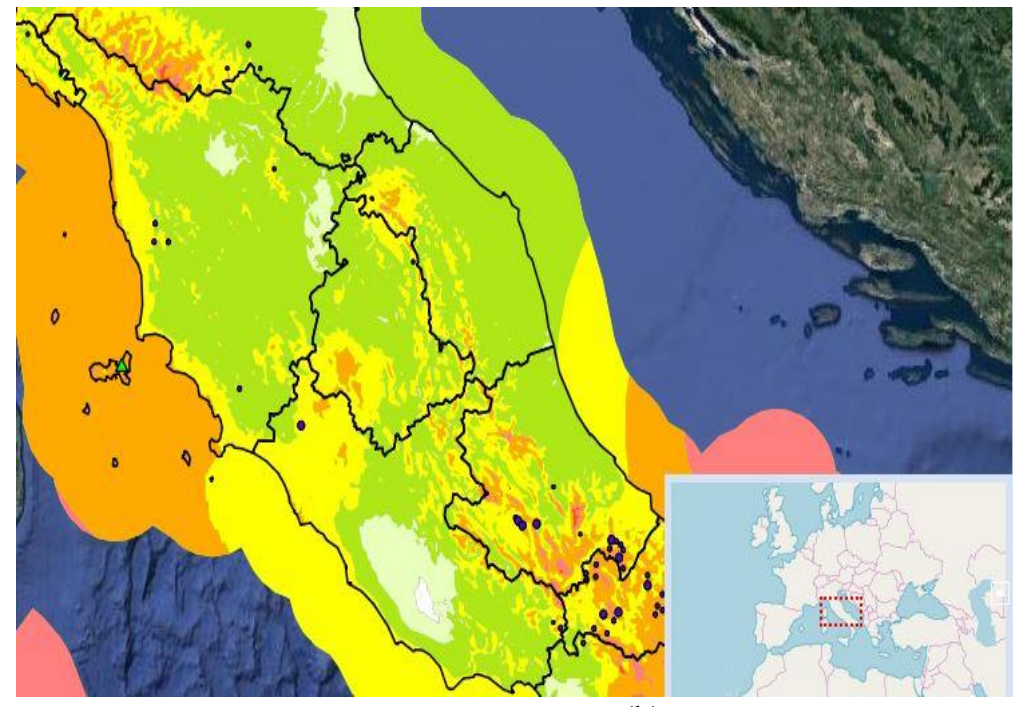

Stazioni anemometrich RSE-RdS - attive $\Delta$ Impianti Eolici esistenti su base comunale . $\$ 5 \mathrm{MW}$ - $5.20 \mathrm{MW}$ $\rightarrow 20 \mathrm{MN}$ Velocità media annua del vento a $75 \mathrm{~m}$ s.l.t. $/ \mathrm{s} . \mathrm{I} . \mathrm{m}$. $<3 \mathrm{~m} / \mathrm{s}$ $3.4 \mathrm{~m} / \mathrm{s}$ $4.5 \mathrm{~m} / \mathrm{s}$ $5.6 \mathrm{~m} / \mathrm{s}$ $6.7 \mathrm{~m} / \mathrm{s}$ $7.8 \mathrm{~m} / \mathrm{s}$ ㄷ. $8 \mathrm{~m} / \mathrm{s}$ $9.10 \mathrm{~m} / \mathrm{s}$ $10.11 \mathrm{~m} / \mathrm{s}$ D $>11 \mathrm{~m} / \mathrm{s}$ Confini Regionali

(b)

Figure 1. (a) Wind-power wide circulation; (b) calculation of potential energy production in Magliano in Toscana (see references) 

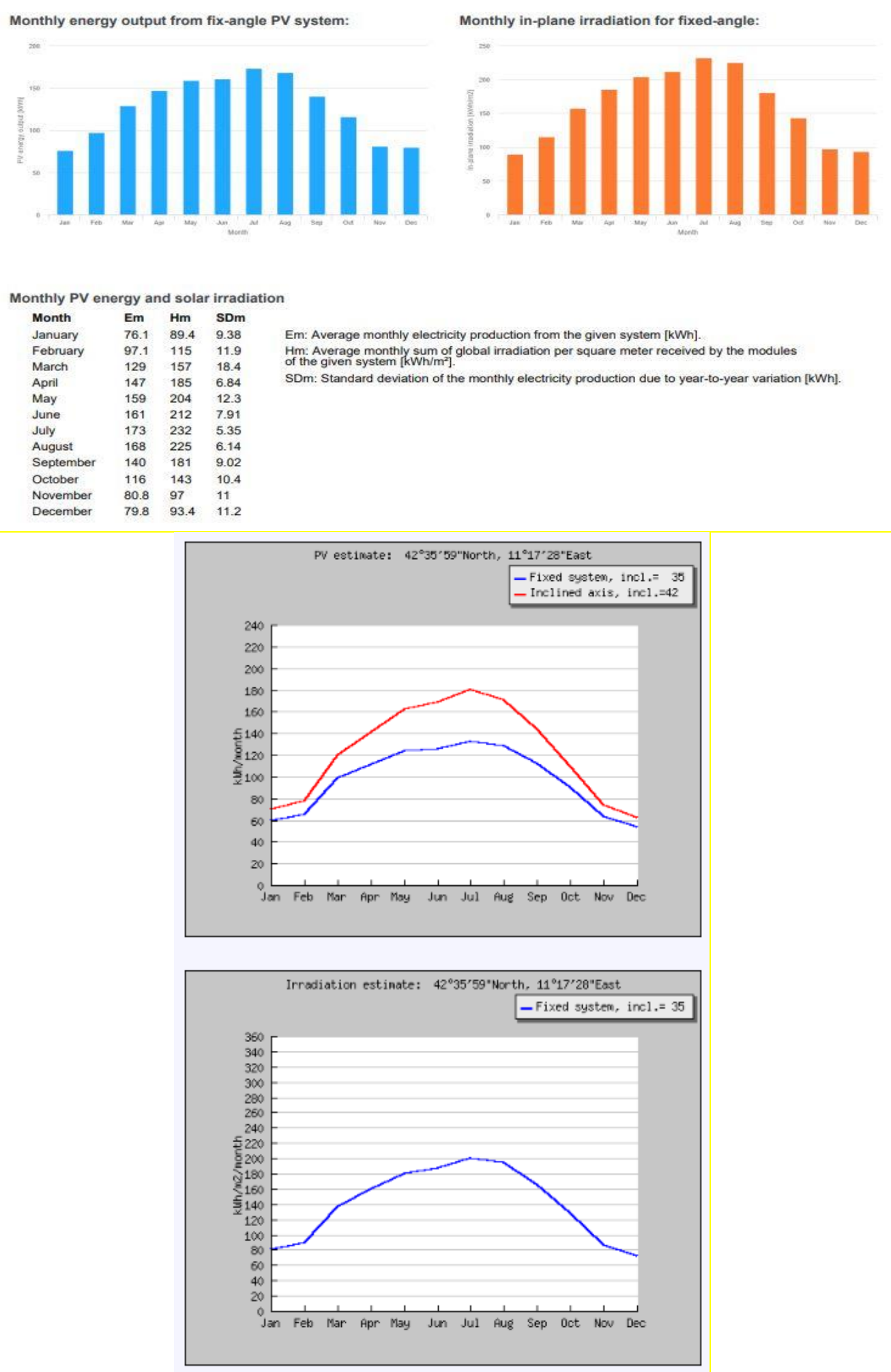

Figure 2. Solar irradiation used for the calculation of potential energy production in Magliano in Toscana (see references)

The aforementioned collaborative and study sharing approach between INGV and the Municipality of Magliano in Toscana (GR) and an energy-environmental and business engineering university department represent its basic and partial data set hinges. The area of study of the municipality is characterized by potentials of energy density both electrical and thermal $\left[\mathrm{MWh}_{\mathrm{e}} /\right.$ hectar/year] and $\left[\mathrm{Mwh}_{\mathrm{t}} /\right.$ hectar/year] of use of RESs, energy storage, biomass sources and energy efficiency developments (including low or medium enthalpy geothermal energy, (i.e., $[13,14])$, in order to provide a precise and detailed energy picture in evolution, as visible by citizens by an ICT summary panel in the main square of the city, calculating the $[\mathrm{MWh}] \mathrm{e}, \mathrm{t}$ produced, that is consumed and the emitted GHGs, as avoided in the atmosphere with respect to the ancient no-low carbon technologies. The new studies and calculations add to the calculation of the potential of electrical and thermal energy density $\left[\mathrm{MWh}_{\mathrm{e}} /\right.$ hectar/year] and $\left[\mathrm{Mwh}_{\mathrm{t}} / \mathrm{hectar}_{\mathrm{ye}} \mathrm{yer}\right]$ in the already studied Italian regions, however they should be developed in greater detail in the single municipalities as they require the "Smart Cities and Communities" calls, duly modified towards the "Smart Ancient Cities" in the European calls for HORIZON 2020. 


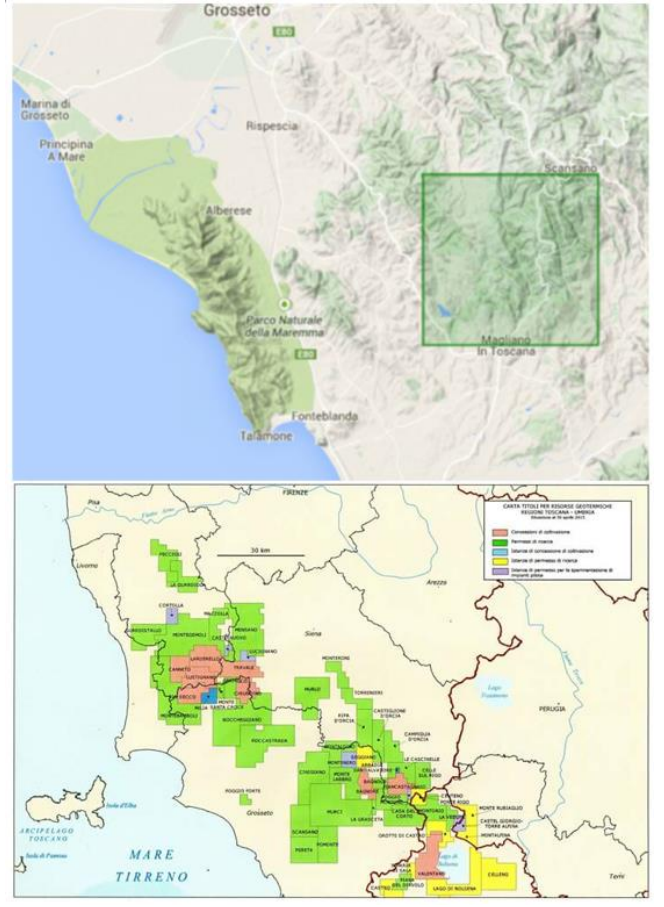

Figure 3. Geothermal permits in the territory of Toscana

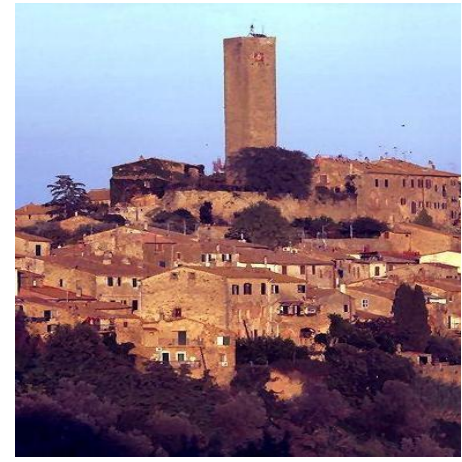

(a)

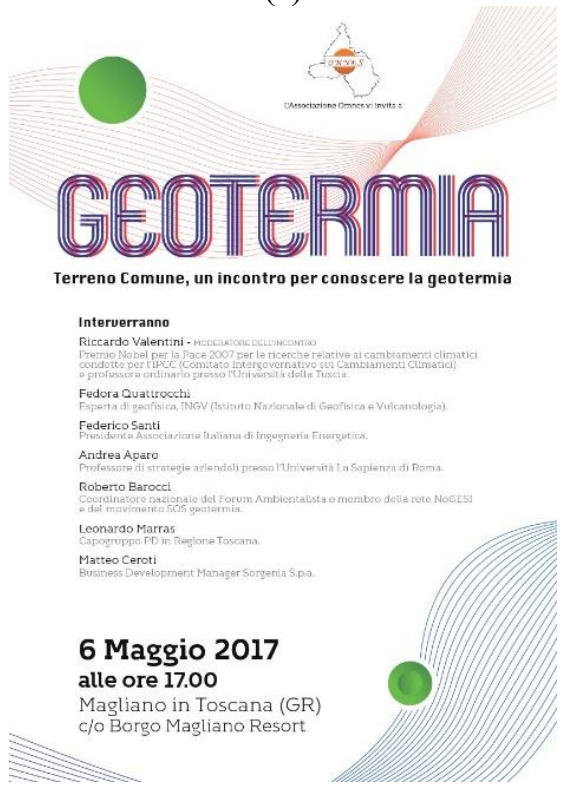

(b)

Figure 4. (a) A picture of Magliano in Toscana where is possible to see what kind of structures exist to improve the RESs, as photovoltaic paints or mini-wind flags devices and

(b) the public event on the Pareda Geothermal Permit possible area, on May, 6, 2017
The various operational and potentially operational energy supply chains have been classified for the Municipality in question by 2025 , but we premise that the environmental and energy assessments are reported in terms of actually produced quantities and those that can be produced later for an intervention aimed at improving the low-carbon energy production of the municipality and we will report everything

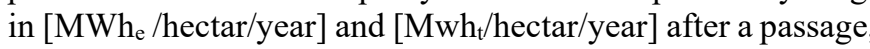
for the municipal buildings considered, in units of measurement originally of $\left[\mathrm{kWh} / \mathrm{m}^{2 *}\right.$ year] or according to the consumption data provided by the municipality.

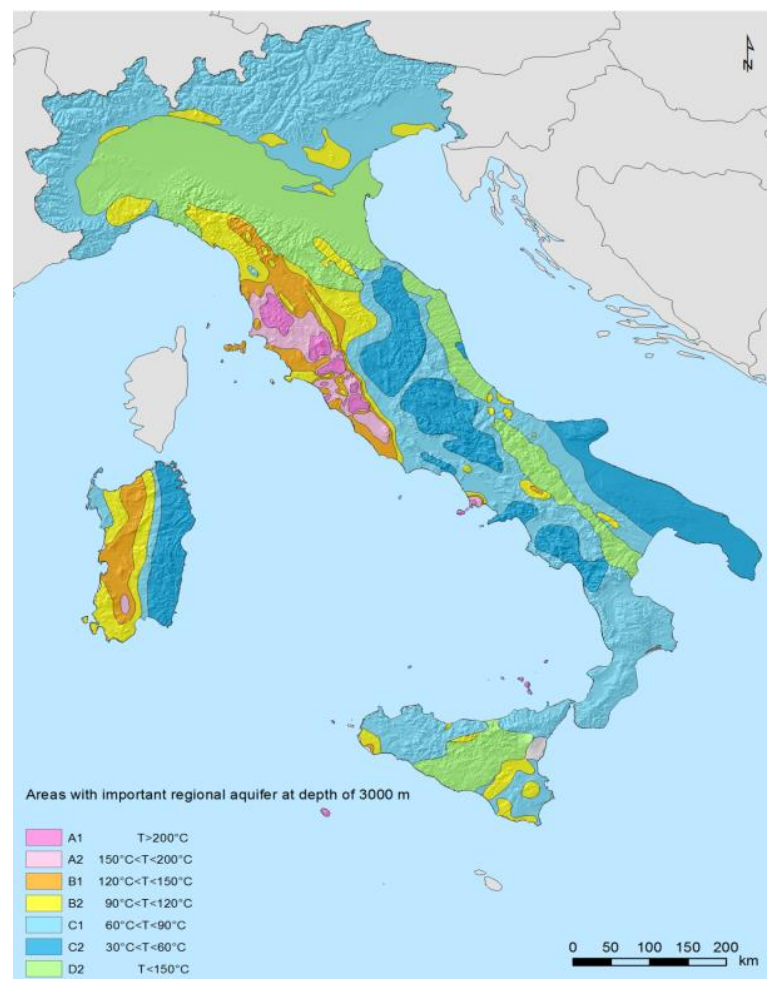

Figure 5. Areas with important regional aquifers at depth of $3000 \mathrm{~m}$ in Italy (see Reports of Progetto Finalizzato

Energetica (PFE) at CNR during the ' 80 and the original paper for the maps $[8,9]$

A chaotic situation is ongoing in Italy as regards the units in which the energy consumption data are reported, rendering almost impossible now a comparison among municipalities. This obstacle should be overcome by this unique variable introduced here. The current situation is illustrated, and, subsequently to actions to increase energy efficiency and the addition of RESs, low-enthalpy geothermal energy [14] and more, future prospects with associated improvements and energy savings.

The objective of the study of the chain of buildings, infrastructures and installations is to carry out an energy analysis of them as found in the territory of the municipality; from these, a unitary "energy producibility" or "energy density" variables are extrapolated from the original available chaotic data (Penu, = electric and thermal $\mathrm{kWh} / \mathrm{m}^{2 *}$ year), which are our benchmark for energy requalification and efficiency improvement of the structures, or for an energy improvement and a reduction of $\mathrm{CO}_{2}$ emissions in the municipality of Magliano in Toscana. From here the foundations are laid to improve the on-line ICT synoptic of the daily electricity production and at the same time of the GHGs emissions avoided in the atmosphere with the new energy expedients of 
the Municipality itself.

A second parameter for the analysis is the "unit energy cost" from the original available chaotic data in the Municipality archives $(\mathrm{Cenu},=$ euro $/ \mathrm{kWh}$ ) expected compared to the real one paid in recent years (experimental data of the Municipality of Magliano in Toscana). The thermal and electrical analysis in question was differentiated according to the operating sectors. In this sector the municipal buildings and schools present in the Municipality area have been analyzed; focusing on RESs and, in particular on photovoltaic and solar thermal. We refer to small plants that include the whole generation with an installed power lower than $30[\mathrm{~kW}]$.

The new technologies are then analyzed one by one, verifying the possibility of their implementation to the Municipality of Magliano in Toscana.

From the data provided by the Municipality and which have been subjected to analytical and critical review (compilation work), it appears that in the last year the elimination of obsolete thermal machinery took place, replaced by highperformance heat pumps. Through energy efficiency actions we want to make all the public facilities belonging to the Municipality and schools self-sufficient.

The average annual production in $[\mathrm{kWh} / \mathrm{kWp}]$ is quite optimal and, after an energy efficiency intervention, the small municipal needs have been met. Recently, low-consumption heat pumps (Hitachi) have been introduced to the municipality, used for the heating of the premises and for the production of ACS (Acqua Calda Sanitaria, in English DHW) in the municipal building, however the efficiency actions should continue and precisely: by inserting solar thermal or photovoltaic on the roofs of municipal buildings such as library, town hall and schools. In fact, with the solar thermal, it would meet the needs of ACS (DHW) production for the building and if it were not available due to any failure, lowconsumption heat pumps would come into operation, which in turn could be energetically powered with photovoltaics, making the system is completely autonomous and renewable. An evaluation of the potential energy production, including the mini-wing flags devices on the castle and walls, was performed partially as a function of the permits released by the "Sovra-Intendenza alle Belle Arti". The Vision of the "Rigenerated Ancient Walls and Castles to produce Energy" (see Quattrocchi et al. presentation at the Nocera Inferiore (SA), meeting "Muse and Musei", on 10/10/2015) would consist in the development of the applications of "graphene" and of nanotechnologies for the production and storage of electric energy in contexts of particular landscape and ancient edifices of historical interest, where it is necessary to minimize the impact on the landscape-architecture, extremely relevant. The graphene film, applied to historical walls, as well as to serve to produce energy, could also constitute an invisible but very effective barrier to the infiltration of meteoric water. Water, in fact, percolating inside the historic walls removes the mortar (binder), weakens its structure and relatively quickly causes very serious damage, which can also cause it to collapse; precisely on this issue a problem that has had to be faced recently concerns the collapses of some parts of these historic walls, therefore the idea of operating on them, would initially focus on a restructuring, to then conduct an energy requalification. Moreover, this graphene film could mask the structural "anchors" the enhance strength to the ancient walls, but that could be hidden by photovoltaic devices on. Another application considered therefore is the "photovoltaic" paint, which is very well applicable, for example, on some historic walls of an ancient village, as they are invisible and without particular environmental impact, capable of capturing the sun's rays and transforming them into energy, to satisfy small needs. An excell table was produced, which can be used directly in the future for all ancient villages, simply by varying the walls perimeter length and height of the walls as well as articulating an ArchGIS of the masonry, to be "energized" and protected, with photovoltaic paints.

Furthermore, it was verified whether a certain perimeter of pavement construction could be carried out with a very low environmental and landscape impact - albeit an energy producer - we refer to the technology of piezometric tiles, which trampling them, in a certain area of intense passage of people (commercial high-frequentation pathways, etc ...) produce low-carbon energy. The cost of these energyenvironmental applications, currently unthinkable because it is still without a market and without real incentives, could decrease in a short period of time and have a virtually zero impact on the landscape, as well as being fun for schools and "environmental events". This solution could therefore be applied in an undifferentiated manner throughout the municipal area (local roads, trekking paths, river banks, etc.).

Some data on public lighting in the Municipality of Magliano in Toscana were analyzed, with the aim of further improving low-carbon electrical energy production and reducing oxidised $\mathrm{CO}_{2}$ emissions.

From the data provided by the Municipality of Magliano in Toscana, it is possible to summarize individual and total power and quantity of all the light points, in the primordial phase, i.e., before the intervention and after the replacement of the lamps with LED technology. After the redevelopment of the bodies belonging to public lighting, an average annual saving of 97 tonns of $\mathrm{CO}_{2}$ was calculated.

Energy Diagnosis of buildings in the Municipality of Magliano in Toscana was carried out, in particular of two school buildings, namely: kindergarten and elementary school and middle school.

For the eolic application of this energy source, were considered 2.0 MW wind turbines. The hours of equivalent operation for wind turbines can be assumed equal to $\mathbf{1 5 0 0}$ hours per year, while the specifications of the $\mathbf{V 8 0}$ are shown in the table/figure below.

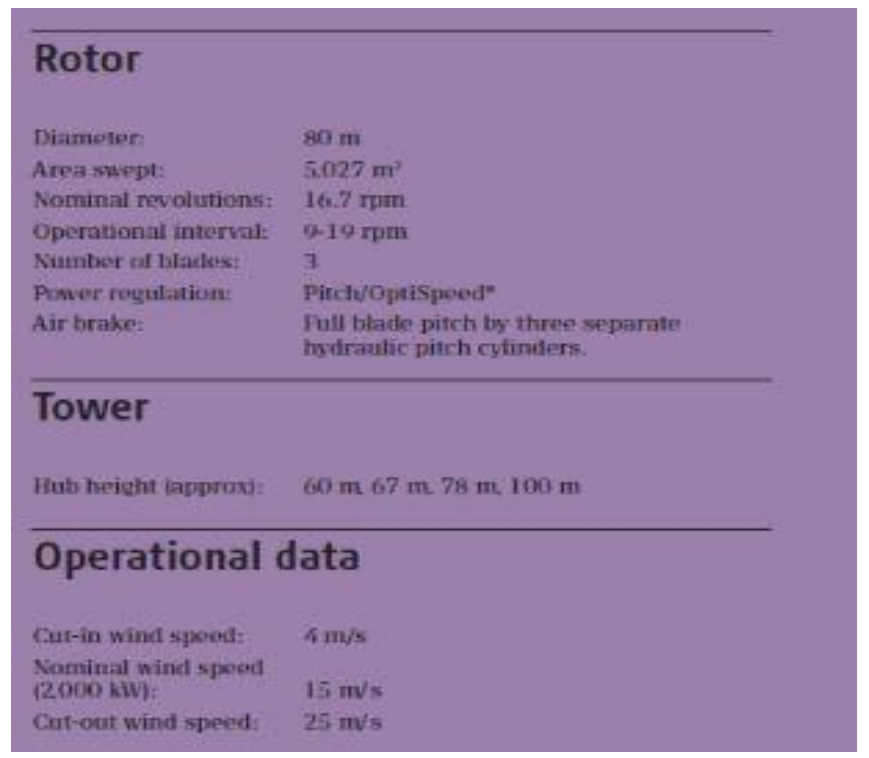

Figure 6. Analytical data of the eolic machine 
The distance between two wind turbines has been chosen on the basis of the current legislation, which fixes it, according to the diameter of the wind turbines $(\Phi=\mathbf{8 0 m})$, according to the diagram shown

We want to maximize the plant efficiency trying to locate as many wind generators as possible in the area examined (in compliance with the correct operational functionality) without taking into account all existing regulations relating to environmental protection and landscape impact.

\section{HYPOTHESIS 1:}

The area in which the location of two different wind turbines is planned will be $\boldsymbol{A t o t}=D 1 \times D 2=7 \emptyset \times 4 \emptyset=$ $[7 \times(80)] \times[4 \times(80)] \cong \mathbf{1 8 0 0 0 0 ~ m q}$.

Considering a power $\mathbf{P}$ for each wind generator equal to 2MW and a number of hours of operating equivalent $h$ equal to 1500 hours/year, results:

$$
\begin{aligned}
& \text { Energy density value }=P \times h \div \text { Atot } \\
& =2 \times 1500 \div 180000 \cong \frac{0,17 \text { GWh }}{\boldsymbol{h a} \cdot \boldsymbol{a n n o}}
\end{aligned}
$$

\section{HYPOTHESIS 2:}

The distance between two different wind turbines is planned will be $\boldsymbol{A t o t}=D 1 \times D 2=7 \emptyset \times 1=[7 \times(80)] \times 5 \mathrm{~m} \cong$ 2800 mq.

Considering a power $\mathbf{P}$ for each wind generator equal to 2MW and a number of hours of operating equivalent $h$ equal to $\mathbf{1 5 0 0}$ hours/year, results:

$$
\begin{array}{r}
\text { Energy density value }=P \times h \div \text { Atot } \\
=2 \times 1500 \div 2800 \cong \frac{10,71 \text { GWh }}{\boldsymbol{h a} \cdot \boldsymbol{a n n o}}
\end{array}
$$

Photovoltaic:

Constant values:

- Land area available for installation $\left(\mathbf{A}_{\mathbf{t o t}}=10000 \mathrm{~m}^{2}\right)$

- $\boldsymbol{\eta}=0,95$ (occupation coefficient of land)

- $\boldsymbol{\eta}_{\mathbf{p}}=16 \%$ (Average annual efficiency of monocrystalline silicon panel)

- $\mathrm{N}^{\circ}$ of hours equivalent of operation $(\mathrm{h}=1300$ hours/year)

- Total irradiation per square metre (Grosseto) (I= $1504 \mathrm{KWh} / \mathrm{m}^{2}$ year)

HYPOTHESIS 1: all calculation procedures are carried out trying to optimize as much as possible the area occupied by this plant at the expense of energy density.

Net surface occupied by panels $\left(A_{p}\right)=7000 \mathbf{m}^{2}$

For each hectare of land you will then have the following energy density value:

$$
\begin{aligned}
& \text { Energy density value }=A p \times \eta \times \eta_{p} \times I \\
& =7000 \times 0,95 \times 0,16 \times 1504 \\
& \simeq \frac{\mathbf{1 , 6} \text { GWh }}{\boldsymbol{h a} \cdot \text { anno }}
\end{aligned}
$$

HYPOTHESIS 2: This consists in considering a system characterized by a layout of the photovoltaic panels more spaced than the previous case, according to this configuration:

$\mathrm{X}=1 \mathrm{~m}$ (element lenght)

$\beta=30^{\circ}$ (corner of inclination)

$\mathrm{D} 1=\mathrm{X} \cos \beta=0,876 \mathrm{~m}$ (horizontal projection)
$\mathrm{H}=\mathrm{X} \sin \beta=0,5 \mathrm{~m}$ (height)

$\mathrm{D} 2=\mathrm{H} \tan (\delta+\mathrm{L})$ with $\delta=23,5^{\circ}$ winter solstice declination;

$\mathrm{L}=$ latitude

$\mathrm{DTOT}=\mathrm{D} 1+\mathrm{D} 2=3 \mathrm{H}=1.5 \mathrm{~m}$

Net surface occupied by panels $\left(A_{p}\right)=4000 \mathbf{m}^{2}$

For each hectare of land you will then have the following energy density value:

Energy density value $=A p \times \eta \times \eta_{p} \times I$

$$
\begin{aligned}
& =4000 \times 0,95 \times 0,16 \times 1504 \\
& \cong \frac{\mathbf{0 , 9 1 4} \boldsymbol{G W h}}{\boldsymbol{h a} \cdot \boldsymbol{a n n o}}
\end{aligned}
$$

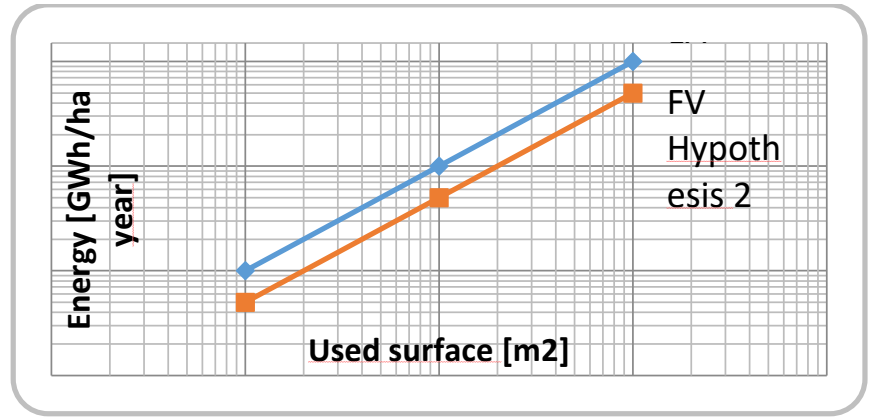

Figure 7. Surface used as a function of energy produced

Finally, the investments to be carried out in the next imminent years (energy planning) to make the structures energy efficient were assessed, with a relative reduction in atmospheric GHGs emissions and an increase in renewable energy applied to annual energy production, with the replacement of obsolete machinery and systems.

It is important to remember that the municipal building par excellence is an existing building and that the energy performance must be compared with similar existing buildings, as for public buildings built starting from 2018 the reference value is that of NZEB (Nearly Zero Energy Building), or almost zero energy buildings.

The work overviews the future need of the Luigi Vivarelli Biomass-Biomethane energy production (more than $100 \mathrm{MW}$ ), planning to write a specific EU project mostly for the optimization of the bio-methane path along the plant, and associated software, and further thesis degree should be dedicated.

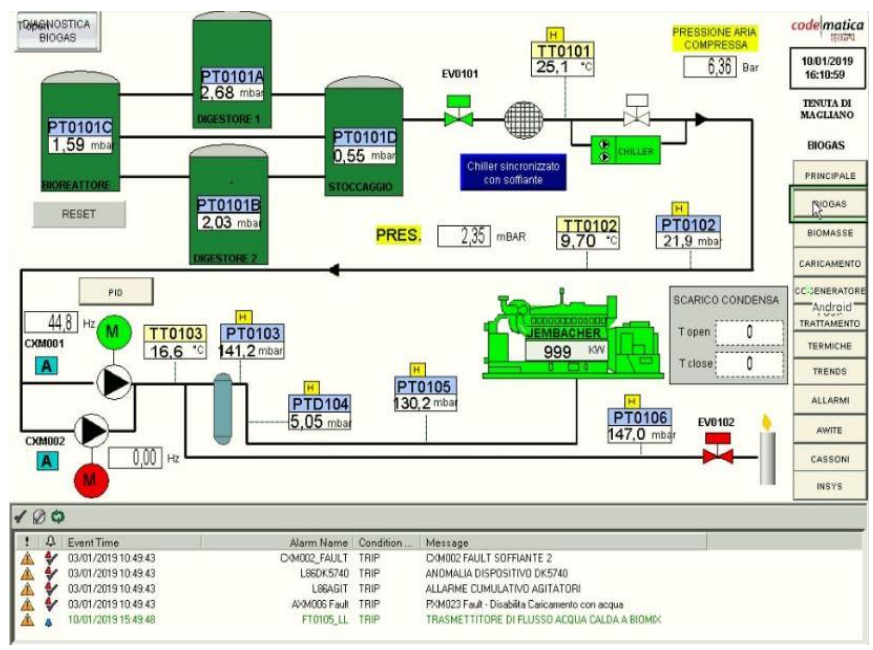

Figure 8. Implementation of the software for remote control of the biomass plant 
Every day, by burning 600 tonnes of product, $24000 \mathrm{~kW}$ are injected directly into the network. The incentive in this system stems from the fact that for 15 years the sale of the energy produced has been set at $0.28 \mathrm{~kW} / \mathbf{h}$.

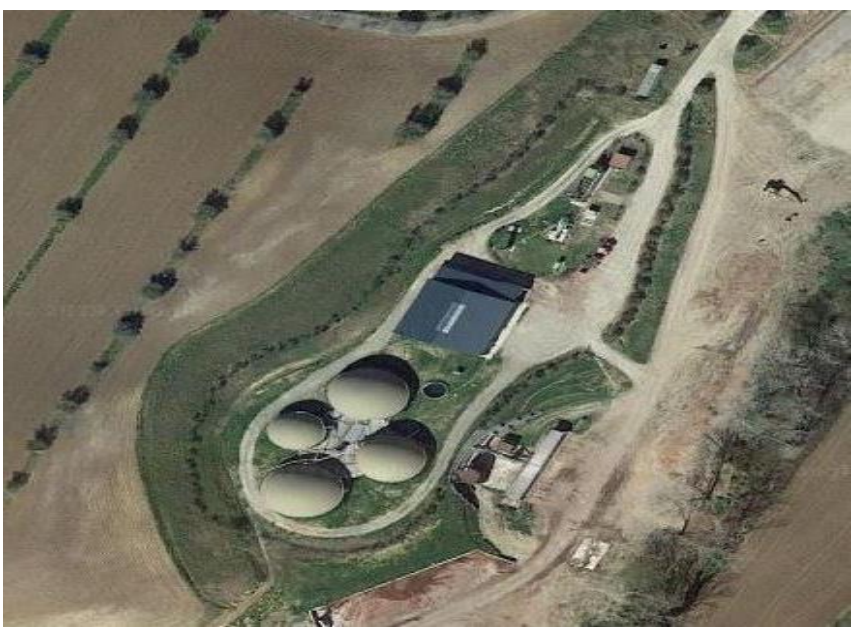

Figure 9. Satellite overview of the Luigi Vivarelli Enterprice biomass power plant in Magliano in Toscana

The issue of medium-enthalpy geothermal energy in the Magliano in Toscana Municipality, to produce energy is still under discussion to the Authorities: after the stop to the permits to perform deep drilling in 2015, for private companies, the binary-cycle medium-enthalpy geothermal energy in Tuscany still represent a fair, as a consequence of the "speculation" and no-ethical behavior of certain little companies, among them born in Fiscal Paradises of Europe. In particular, in this area there is the Pareta Permit for drilling at $3500 \mathrm{~m}$ depth, by the Enterprice Futuro Energia S.r.1., which in 2011 asked to extend the permit of exploration to Scansano and Orbetello too and renewed the Pareta Permit on 09/03/2017, while other operators are interested too: Terra Energy, for the Pomonte area and Enel Green Power S.p.A. for the Murci sector, to increase complessively to $150 \mathrm{MW}$ installed in the Magliano in Toscana area. Almost 18 are the permits in the Grosseto Province and 34 in the Region as a whole. Inside the Magliano in Toscana Municipality, the citizens asked a scientific consulting to the Major of Staufen, Michael Benitz - an ancient city in the Black-Forest-Germany with 7500 lived people, damaged during a shallow geothermal drilling, due to swelling and fluid movement, possibly analogue to that foreseen for the Pareta Permit. Only eliminating the "speculative enterprises" and the jointed university and research centers no-ethic professors and "relative" researchers (the case histories are on newspapers and see also comdifesaterritorio@gmail.com and public event on $06 / 05 / 2017$ ) it is possible to re-start to develop this chain of geothermal exploitation. The Regional Council of Tuscany, on $01 / 02 / 2017$, constraints the "Giunta Regionale" to define on the regional territory the areas sound to install mediumenthalpy geothermal projects (see Risoluzione Parlamentare delle Commissioni Riunite VIII e X, Camera dei Deputati del 15.04.2015 ongoing for two years http:/unmig.sviluppoeconomico.gov.it/unmig/geotermia/zon azione.asp.). The road is still long, at least in Italy, if the research centers and university are highly ethical and in the mean time, at the moment local citizens do not trust in them.

\subsection{Canary Islands: $100 \%$ renewable "El Hierro"}

The Canary Islands are an archipelago composed of 9 islands, 7 large and 2 smaller. They are located off the northwest African coast; they are all of volcanic origin. Given their strategic position and their structural conformation, they are suitable for the installation of technologies that produce energy from the various renewable RESs, such as the heat present under the earth's surface but in particular the wind, the sun (the sea-wave motion could also be exploited).

El Hierro, the smallest island in the Canaries, which covers about 250 square kilometers, has become, for some years, a point of reference for all those places in the world that intend to feed their activities exclusively with clean energy. The geographical conformation of the island is very varied, given that it passes from the top of Malpaso $(1500 \mathrm{~m}$, therefore a greater height than the hill of Magliano in Toscana that does not exceed the $400 \mathrm{~m}$ of height) up to $300 \mathrm{~m}$ of depth below the level of sea of the marine reserve of La Restinga; this landscape has been used for the construction of a hybrid hydro-wind system that can satisfy the energy needs of the population, avoiding the emission of approximately 18700 tons of $\mathrm{CO}_{2}$ and the use of 40,000 barrels of oil for the diesel plant. The wind farm consists of 5 blades of $1.2 \mathrm{MW}$ each and its production remains almost constant throughout the year [Mwhe/hectar/year of approximately 1500 hours]. The artificial lake, located a short distance away, acts as a hydraulic deposit and thanks to the energy it can receive from the wind turbine blades it acts as a pumping station, which brings water back to the upper basin, and which is useful for balancing the electricity grid in the moment of lack of wind sources. In addition, there is also a diesel power plant for emergencies that was the old power source to meet the needs.

\subsection{Review of the geothermal exploitation in the Canary Islands}

The Government of the Canary Islands could possibly largely neglecting its geothermal potential despite known since 40 years, when the Geological and Mining Institute of Spain (IGME, at the beginning with the national company Adaro, for geothermal exploration in the Canary Islands in the '80) carried out various explorations in Lanzarote, Gran Canaria, Tenerife and La Palma. At present state of art, geothermal for power generation is completely blocked due to the situation of the Spanish electricity sector and the ongoing discussions around a new regulatory framework. Spanish geological setting is very favorable for the development of EGS (Enhanced Geothermal System, to produce energy: the areas considered are [16] the tectonic grabens of La Selva and Vallés in Cataluña, areas of deep fracturing in Galicia, the tectonic grabens in the SW of Salamanca (towns of Ciudad Rodrigo and Tormes), fractured areas west of Cáceres, the borders of the Tagus River depression, which are characterized by largescale fractures that affect the Hercynian bedrock and lastly, areas in Andalucía where the granitic or Paleozoic bedrock is highly fractured, such as Sierra Morena or the more internal zone of the Bética Ranges in the vicinity of Sierra Nevada). In any case these projects development is subject to an improvement of the regulatory and market conditions, limitating the active projects only in the low-enthalpy direct uses 
Some Spanish geological experts stated that "Lanzarote has enough geothermal resources to generate all the energy consumed by the island and Fuerteventura," , from about $450 \mathrm{MW}$ installed (i.e. high enthalpy pilot project for Lanzarote, Fuerteventura, see the declarations of the Geothermal Technology and Innovation Platform GEOPLAT) creating a Geo-Education for a Sustainable Geothermal Heating and Cooling Market (GEOTRAINET) mostly for the low-enthalpy resources.

Experts believe that Timanfaya thermal anomalies on the surface could be exploited to produce energy (http://ieagia.org/workshop-presentations/2019-gran-canaria-

geothermal-energy-workshop/, https://www.energiasrenovables.com/geotermica/hay-geotermia-suficiente-engran-canaria-como-20190313,

http://geothermalresourcescouncil.blogspot.com/2019/03/spai n-geothermal.html. "Geothermal energy can generate $30 \%$ of clean energy in the Canary Islands and given it back," said recently the president of the Cabildo of Gran Canaria, Antonio Morales, the presentation of a recent conference, in which also involved experts from the Technological Institute of Renewable Energies (ITER) and the Geological and Mining Institute of Spain (IGME), among others.

The archipelago of the Azores, which belongs to Portugal and is not that far from the Canaries, has though been able to top into its geothermal resources, deriving today about $22 \%$ of its energy demand from geothermal resources. Obviously, as elsewhere, the low-enthalpy resources are located where-ever in the Canary Islands. For now, the Canary government has been granted EUR 900,000 (\$1 million) in subsidies for nine geothermal lowenthalpy projects, which mainly benefit the hotels that use energy for air conditioning and water heating $[\mathrm{MWh}]_{\mathrm{t}}$. Inturn, high-enthalpy geothermal projects to build up an electric power plant, to generate electricity $[\mathrm{MWh}]_{\mathrm{e}}$, are scarce: TERMOVOLCAN is a project to promote the exploration of geothermal resources in the Canary Islands (Department of Earth and Ocean Dynamics of the Faculty of Earth Sciences of the University of Barcelona, which will be carried out until 2021 and has a total budget of over $€ 1,600,000)$. The objective is to design and develop innovative geophysical and geochemical methodologies to improve the exploration of geothermal resources in the islands of Tenerife, Gran Canaria, and La Palma. The highenthalpy geotermal energy here is genetically linked to the unrest volcanic activity of the Canary Islands, with fourteen historic eruptions in the last 500 years, considering also that between 1730 and 1736 an important fissural volcanic eruption took place over a length of $20 \mathrm{~km}$ in Lanzarote, which covered an area of 174 square $\mathrm{km}$, making it the possible only area in Spain with a so high potential for exploiting high-enthalpy geothermal resources, which are capable of producing energy thanks to temperatures of over 200-300 degrees generated beneath the Earth's surface. The most active partners in volved in these researches are the "Technological and Renewable Energy Institute" (ITER), the "Volcanological Institute of the Canary Islands", the "Spanish Geological and Mining Institute" (IGME) and the "Tenerife Island Energy Agency". Some of the geological characteristics of the Canary Islands make it difficult to search for geothermal reservoirs (medium-high enthalpy), as surface manifestations such as thermal springs, fumaroles and abnormal gas or heat emissions are not as evident as in other active volcanic systems, i.e. in Italy.
TERMOVOLCAN will use ancient geochemical techniques to detect areas of the surface with increased permeability to the ascent of fluids of deep origin, such as the analysis of the isotopic composition of helium (used in Italy since the '80), a tool that helps to locate deep heat sources (i.e. around 2-5-3.0 km depth, South East to South of the Gran Canaria, where to perform the drillings, around $6 \mathrm{Ml}$. $€$ value, for each well). Thermal satellite images and geophysical methods such as magneto-tellurics (MT) are foreseen to be used. A 3D map of of the subsurface space of the islands is foreseen to be detailed (see also http://www.fbg.ub.edu/en/news/termovolcan-project-topromote-the-exploration-of-geothermal-resources-in-thecanary-islands/).

These studies followed a lot of studies carried out in Italy in recent decades, hopefully in synergies in fluid geochemistry with the scientific community of the Canary Islands. A magnetotelluric study covered - in the frame of the project the whole island with a first "screening" of around hundred measurements which is followed by the geochemical study of dissolved gases in groundwater in about only 40 wells that have already been analyzed and therefore it is only at the beginning of work. In Italy around 3000 sites were analyzed until now for the same purposes, i.e. in Lazio, Umbria, Tuscany, etc. $[8,9]$.

The Australian company Petratherm has performed a first phase of a large magneto-telluric survey on the Island of Tenerife, Canary Islands, to determine if the target clay cap is suitable for geothermal drilling and development

The Shallow HDR geothermal field in Lanzarote - Canary islands did efforts to evaluate the potential evaluation and heat extraction tests (EU Project https://cordis.europa.eu/project/rcn/1884/factsheet/en, with coordinator Tecnología y Recursos de la Tierra SAL, Madrid, Spain). The aim of the project is to evaluate the geothermal potential of a $10 \mathrm{~km}^{2}$ large area situated in the Timanfaya National Park of Lanzarote, with a view to future electricity generation via heat exchangers. Several areas with surface temperatures of 100-180 C and of 300-600 C at only 5 meters depth have been studied recently. The heat transfer model presently established for this area is based on gases and dissolved gases $\left(95-98 \% \mathrm{~N}_{2}, 0.5-1 \% \mathrm{CO}_{2}\right)$ reaching easily the surface by convection transport. The water vapour content detected on the surface is very low $(0.0003-0.0020 \% \mathrm{Vol})$. Heat-flow density of each geochemical anomaly and of the entire system were started to be evaluated.

The most important Spanish partners involved in the geothermal research in the Canary Islands are: Instituto Volcanólogico de Canarias (INVOLCAN), Agencia Insular de la Energía de Tenerife (AIET), Institute for the Diversification and Saving of Energy (IDAE) Telur Geotermia y Agua, S.A., CEDEX (Centro de Estudios y Experimentación de Obras Públicas), Instituto Tecnológico y de Energías Renovables (ITER), IGME (Instituto Geológico y Minero de España), GEOPLAT (Spanish Technology and Innovation Platform on Geothermal, GEOPLAT 2018 training course: Design of geothermal systems: http://www.geoplat.org/wpcontent/uploads/2018/09/D\%C3\%ADptico-informativocurso-GEOPLAT-Bilbao-24-25-oct.-2018.pdf), Instituto Universitario de Aplicaciones de las Tecnologías de la Información y de las Comunicaciones Avanzadas, Universitat Politècnica de València, TELUR - Geotermia \& Agua, La Palma Research Centre (www.lapalmacentre.eu): strategic synergies with the Italian geothermal scientific community, 
mostly for some important scientists highlighted as positive in the public awareness of the technology, by the population where geothermal projects, are stopped as a consequence of some "geothermal/economic" speculations in which some scientists did not allow a correct path of the geothermal projects, are strongly recommended.

Table 1. Potential Geothermal Resources in Spain mainly located in the Canary Islands [16, 17], excluding the EGS potential: estimated at $60 \times 105 \mathrm{GWh}$, which would allow installing a total power capacity of $745 \mathrm{MW}(\mathrm{e})$

\begin{tabular}{|c|c|c|c|}
\hline $\begin{array}{l}\text { Type of } \\
\text { use }\end{array}$ & $\begin{array}{l}\text { Type of } \\
\text { reservoir }\end{array}$ & $\begin{array}{l}\text { Recoverable } \\
\text { stored heat } \\
\left(10^{5} \mathrm{GWh}\right)\end{array}$ & Power (MW) \\
\hline \multirow[t]{2}{*}{ Thermal } & $\begin{array}{c}\text { Low } \\
\text { temperature } \\
\text { (total } \\
\text { resources) }\end{array}$ & 15,682 & $5,710,320$ (MWth) \\
\hline & $\begin{array}{c}\text { Low } \\
\text { temperature } \\
\text { (usable) }\end{array}$ & 160 & 57,563 (MWth) \\
\hline \multirow{4}{*}{ Electric } & $\begin{array}{c}\text { Medium } \\
\text { temperature } \\
\text { (total } \\
\text { resources) }\end{array}$ & 541 & 17,000 (MWe) \\
\hline & $\begin{array}{l}\text { Medium } \\
\text { temperature } \\
\text { (studied) }\end{array}$ & 54 & 1,695 (MWe) \\
\hline & $\begin{array}{c}\text { High } \\
\text { temperature } \\
\text { (studied) }\end{array}$ & 1.8 & 227 (MWe) \\
\hline & $\begin{array}{c}\text { Enhanced } \\
\text { geothermal } \\
\text { systems } \\
\text { (known } \\
\text { areas) }\end{array}$ & 60 & 745 (MWe) \\
\hline
\end{tabular}

With the exception of the Teide fumaroles, there is not any evidence of hydrothermal fluid discharges in the surficial environment of the Canary Islands, therefore it is strongly necessary to study the diffuse $\mathrm{CO}_{2}-\mathrm{H}_{2} \mathrm{~S}-{ }^{222} \mathrm{Rn}-\mathrm{He}-\mathrm{H}_{2}$ degassing both in soil $[18,19]$ and in dissolved gases of groundwater, widely, after the first screening surveys, performed already. In 2017 were published surveys [16, 17] carried out in five mining licenses in Tenerife and Gran Canaria with the aim of sorting the possible geothermal potential of these five mining licenses. Only volcanohydrothermal/biogenic $\mathrm{CO}_{2}$ in the diffuse degassing at each study area was analysed, while it should be strongly necessary to analyse the most important "convection" signature elements both in soils and groundwater: ${ }^{222} \mathrm{Rn}$ and $\mathrm{He}-\mathrm{H}_{2}$ as "faults pathfinders", where the fracture field and permeability is maximum and closest to the surface. [8-10, 18, 19]. Despite several hundreds of measurements of diffuse $\mathrm{CO}_{2}$ emission, soil $\mathrm{CO}_{2}$ concentration and isotopic composition were performed at each mining license: now it is very necessary to measure the fluxes and concentration of the above-mentioned trace elements, in dissolved gases to as well as to understand the $\mathrm{CO}_{2} / \mathrm{CH}_{4}$ ratio, also in the isotopic signature in the islands, allowing to discover the soundest sectors where to drill. Previous studies highlighted the percentage of the volcanohydrothermal contribution in the current diffuse $\mathrm{CO}_{2}$ degassing was in the range $0-19 \%$. The Abeque mining license, that comprises part of the North-West volcanic rift of Tenerife, seems to show the highest geothermal potential, with an average of $19 \%$ of $\mathrm{CO}_{2}$ being released from deep sources, where to deepen the soil gases analyses of the other abovementioned trace elements to highlight the buried faults (by 222Rn and He mainly). Also Atidama (South East of Gran Canaria) and Garehagua (Southern volcanic rift of Tenerife), with $17 \%$ and $12 \%$ respectively are interesting sites.

\section{DISCUSSION MERGING PRE-EXISTING AND NEW RESULTS}

The results obtained in the various elaborations, obtained also thanks to the collaboration with Italian and Spanish municipal administrations (with particular reference to Magliano in Toscana) and technical office, which have cooperated in order to provide access to the data and information in their possession, are exhibited.

The experience in the technical field acquired during the experimental phase at the Renovables Nueva Era and other companies, both operating in the Spanish territory of Gran Canaria, dedicated to the production of energy from renewable sources (RESs) which allowed to implement the methods and technological applications illustrated above. Comparisons have been made in broad lines between the two different national systems (Italy, Spain) and in general at European level, highlighting the enormous potential to render alive these Smart Ancient Cities located among the sea and a medioevaldefense hill near the sea, as Magliano in Toscana is: these ancient cities are lived only in the summer, while by this new energy-winter tourism implementation the city will be lived in all seasons.

Finally, an evolutionary Vision of the situation is provided, with the aim of raising awareness among the users of municipal services towards good low carbon energy practices to be carried out, finding the main solutions in reducing consumption and greenhouse gas emissions, in the increase of renewable energy production, in accordance with the European objectives set for HORIZON 2020 and for the SET PLAN ENERGY.

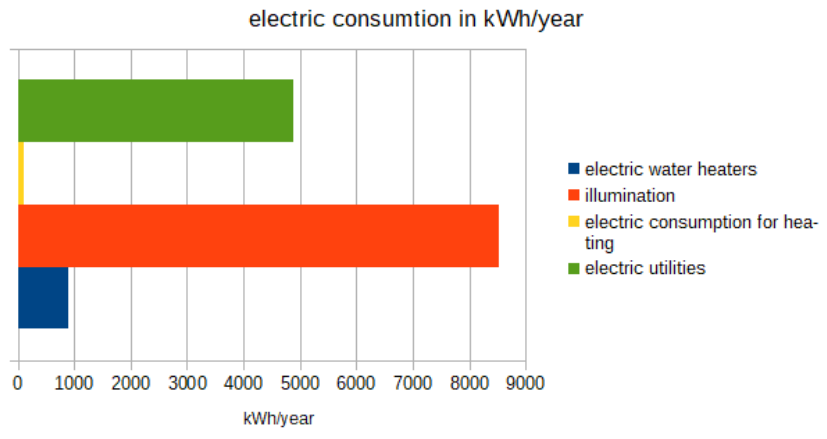

Figure 10. Analytical reworking and summary of the electrical consumption in Magliano in Toscana in [KWh/year]

The results obtained refer to the two examples previously analyzed, in the case of the Primary and Primary School of Magliano in Toscana, which results in the energy class E category, the following energy reference indicator (EPI) was identified: [ $\mathrm{kWh} / \mathrm{m}^{2} /$ year]. It represents the recorded energy consumption values (electricity and heat demand) in relation to the surface unit per unit of time. Only with the same variable unit is possible to compare the studies on this topic. 
The electricity consumption and the thermal consumption were analytically reconstructed to highlight the distribution of the same according to the type of services. The electrical energy consumptions associated with the General Services are mainly due to the lighting of the structure and to the other electric utilities present in the classrooms and in the refectory (PCs, printers, servers, etc.), among which there is the presence of electric boilers used for the production of ACS. In relation to thermal consumption, they are solely attributable to the heating of the structure. The electrical consumptions recorded in order to satisfy the request are to be charged mainly to the lighting, to the motive power for the electric utilities, for the operation of the water heaters.
The thermal consumption is to be attributed exclusively to the heating of the school building (winter air conditioning) and therefore attributable to the General Services. Since there are no other thermal uses, $100 \%$ of the heating LPG is attributable to the winter air conditioning process.

Since electricity consumption and thermal consumption are all attributable to general services, the identified indicator compares energy consumption to the area unit (consumption as $\left[\mathrm{kWh} / \mathrm{m}^{2}\right]$ ). The benchmark of the indicators is therefore similar to the one that can be considered for buildings with similar energy demand values, expressed in $\left[\mathrm{kWh} / \mathrm{m}^{2} *\right.$ year, as defined by the Energy Performance Certificate (APE).

Table 2. Calculation of thermal consumption and relative breakdown by single type of service

\begin{tabular}{|c|c|c|c|c|c|c|c|c|}
\hline Typology & Gen & Feb & Ma & Apr & Ott & Nov & Dec & total \\
\hline Electric consumption [kWh] & 13880 & 39800 & 16381 & 4390 & - & 10275 & 14861 & 99586 \\
\hline Fuel [Sm3 of GPL] & 581 & 1665 & 685 & 184 & 430 & 430 & 622 & 5494 \\
\hline
\end{tabular}

First intervention: The proposal of energy efficiency provides for the replacement of the current lighting fixtures with new LED lighting fixtures, under the same conditions of use (the use of lighting has not been normalised because it does not depend on seasonal factors). The replacement of the current neon lighting fixtures with a power of $36 \mathrm{~W}$ is hypothesized with LED lamps with a power of $18 \mathrm{~W}$. From a technical view it has been hypothesized to replace exclusively the neon tubes with LED tubes, maintaining the current ceiling lights. The cost considered includes the supply of the new lamps and their installation as well as the disposal of the previous lamps to Neon. The discount rate was set at $5 \%$ and the financial calculations were carried out net of any form of incentive, including taxis and with a reference period of 20 years.

Furthermore, the verification of the insertion of brand new ECOTECH GLASS lamps, of exquisitely Italian production, is underway: these are new led glass panels (panel lights) with entirely glass surface and without edges (therefore without abusing the typically Asian metal profiles, also considering the scarcity of the first material), including the ECOTECH BIOVITAE panels that with a technologically revolutionary solution allow to reduce the bacterial load and are therefore ideal for a hospital or in special healthcare / chemical environments (white rooms, ICT rooms etc.). BIOVITAE lamps as a Class I medical device that can be installed in panels of different sizes customized on already existing infrastructures because they can be made to measure. The light emission occurs at certain frequencies, safely preventing outbreaks of infectious diseases, acting on certain molecules the porphyrins - which make the microorganisms allergens share particularly sensitive to a certain type of light, in its photo-catalitic function) for all of Grosseto.
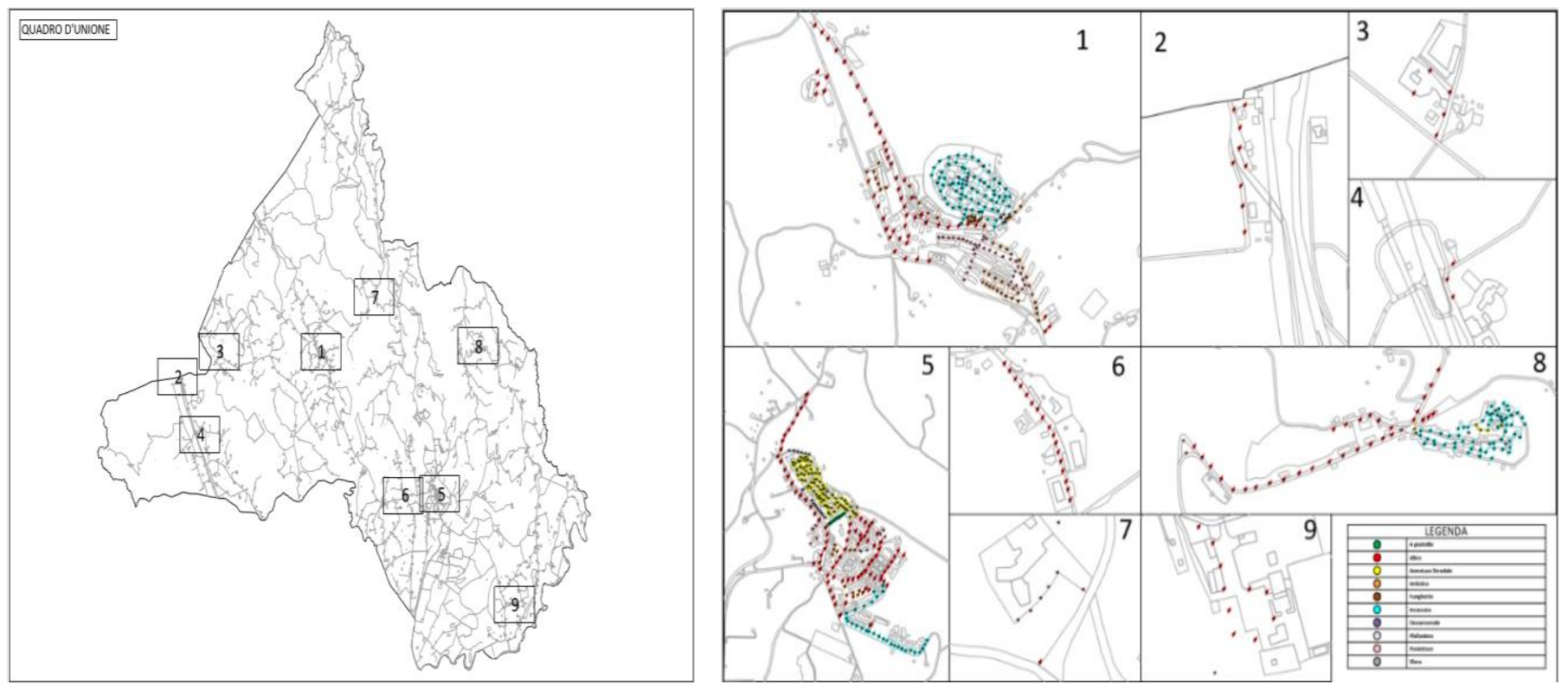

Figure 11. GIS mapping of individual lighting points of the Municipality

Analysis of annual average consumption by sector: We note that during the last four years they have been reduced thanks to renewable applications, but they always remain in the private sector. Therefore, we can calculate in the various sectors the emissions avoided thanks to renewable energy sources: 
Table 3. Consumption and relative breakdown by single type of service

\begin{tabular}{|l|c|c|c|c|}
\hline & $\begin{array}{c}\text { Consumption [kWh] } \\
\text { year 2015 }\end{array}$ & $\begin{array}{c}\text { Consumption [kWh] } \\
\text { year 2016 }\end{array}$ & $\begin{array}{c}\text { Consumption [kWh] } \\
\text { year 2017 }\end{array}$ & $\begin{array}{c}\text { Consumption [kWh] } \\
\text { year 2018 }\end{array}$ \\
\hline $\begin{array}{l}\text { Buildings, tertiary } \\
\text { facilities (non-municipal) }\end{array}$ & 0 & & & \\
\hline Residential buildings & 4786179 & 5024363 & -9566012 & -13971525 \\
\hline Public illumination & 393004 & 406020 & 4973953 & 5145738 \\
\hline Agriculture & 2408470 & 2706021 & 401082 & 387789 \\
\hline Industry & 169687 & 188176 & 2624802 & 2917507 \\
\hline Total & 7757340 & 8324580 & -176159 & 177234 \\
\hline
\end{tabular}

Every $\mathbf{k W h}$ produced by the renewables system avoids the emission of $0.5 \mathbf{~ k g}$ of carbon dioxide. 1 ton of $\mathrm{CO}_{2}=1000 \mathrm{Kg}$ of $\mathrm{CO}_{2}$

A coal-fired power station which is to produce $\mathbf{1 3 3 6 0 . 2 5 6}$
MW/year would emit 6777.128 tonnes of $\mathrm{CO}_{2}$ into the atmosphere, which can be prevented by the application of renewable energy sources which would cancel out GHG.

Table 4. Potential production of $\mathrm{kW}$ for year

\begin{tabular}{|l|c|c|c|r|}
\hline & $\begin{array}{c}\text { Potential production } \\
{[\mathrm{kW} / \text { year }]}\end{array}$ & $\begin{array}{c}\text { Potential production } \\
{[\mathrm{MW} / \mathrm{year}]}\end{array}$ & $\begin{array}{r}\text { Avoided GHG } \\
{\left[\mathrm{Kg}_{\mathrm{g}} \text { of } \mathrm{CO}_{2}\right]}\end{array}$ & $\begin{array}{r}\text { Avoided GHG } \\
{\left[\text { ton of } \mathrm{CO}_{2}\right]}\end{array}$ \\
\hline BIOMASS & 8760000 & 8760 & 4380000 & 4380 \\
\hline $\begin{array}{l}\text { PHOTOVOLTAIC } \\
\text { (hypothesis 1) }\end{array}$ & 1600256 & 1600,256 & 800128 & 800,128 \\
\hline EOLIC & 3000000 & 3000 & 1500000 & 1500 \\
\hline TOTAL & 13360256 & 13360,256 & 6680128 & 6777,128 \\
\hline
\end{tabular}

Therefore energy efficiency improvement inside the PAES document, also depends on the choice of materials: in this case (IP65 glass), i) reduced thickness; ii) resistance to abrasion with protection up to 200 times higher than normal plexiglass; iii) scratch and abrasion resistance over time and high stability over time; iv) reduced light absorption; v) efficient heat dissipation, from the geometry of the layers of the chosen material and the diffusers with very high transparency and energy efficiency (increased by $90 \%$ compared to the classic illuminators in the workplace); vi) high antistatic protection capable of dissipating up to 1000 times the amount of static electricity of normal plexiglass; minimization of cleaning; usability in any environment.

Second intervention: The second solution to improve efficiency is represented by the replacement of the old boiler with a condensation combined with the installation of thermostatic valves on the radiators. The current management of the delivery temperature which can be modulated as a function of the external temperature, combined with the thermostatic valves, would make it possible to optimize the operating temperature of the supply water and to have a return water temperature conducive to condensation, while maintaining the current radiators. The discount rate was set at $5 \%$ and the financial calculations were made net of any form of incentive, including VAT (which represents a cost for the public body in question) taking into consideration a reference period equal to 20 years.

Third intervention: analyzed for the three buildings: nursery and primary school, middle school and municipal building.

Using photovoltaic software, the production values obtained were calculated by entering the data, needs and climate zone of the Municipality of Magliano in Toscana and for the individual buildings that we will analyze. All measurements are in $\left[\mathrm{kWh} / \mathrm{m}^{2 *}\right.$ year $]$ and an example is given for a building in Magliano in Toscana.

Further design analyzes were carried out with the collaboration of foreign companies: RENOVABLES NUEVA
ERA and KEC MEDIO-AMBIENTE, which deal with renewable technologies such as the production of energy from photovoltaic panels, at family level with medium-small installations, but above all at hotel sea district level, reaching medium-large size systems that can meet the energy and water requirements required in a renewable manner. At the same time, it treats the production of Domestic Hot Water (ACS, DHW) using solar thermal technology; air-conditioning of buildings, air-conditioning of private or hotel swimming-pool complexes, use of heat pumps, air-to-air or high-temperature air-water machines.

As part of the activity carried out in the company, an engineering analysis of the various technologies and means with which to compensate for an excessive production demand. Concretely, the work was to physically go to the workplace by analyzing installations that had already been completed and others under construction, however installation projects were also carried out with subsequent start-up and maintenance operations on systems that had already been in operation for years. One of these analyzes concerned the Roca Negra Hotel in Agaete, a structure that is being extended, with an ACS production system using heat pumps supported by a high temperature machine with a $\mathrm{COP}=7$, all integrated with renewable energy coming from solar source, or with solar thermal panels on the roof of the building. In addition to an analysis of the elements that make up the installation there is the economic part of the investments and the creation of estimates. Another project is the one on the Serenity Hotel, for the air conditioning of the pool, for the production of DHW and to meet the energy needs of the same structure, thus making it energy efficient and sustainable. For the design, the Solidworks ${ }^{\mathrm{TM}}$ or Sketchup ${ }^{\mathrm{TM}}$ software is used, which refers to the BIM methodology to provide a clear and precise 3D idea of the project in general. We are talking about a hotel with 40 houses, so with an average of $80-100$ people inside; the average diary consumption of a person is fixed at 55 liters/person which for legislation must be provided at a temperature of $60{ }^{\circ} \mathrm{C}$, due to a legislative issue arising from 
the danger of legionella, a bacterium that proliferates at temperatures $35-45^{\circ} \mathrm{C}$. There are two swimming pools, one for adults and one for children. The installation thus calculated must consist of 45 solar thermal collectors, of which 24 are used for the production of DHW and 21 to air-condition the pool, of which we consider there is a loss of $2.5^{\circ} \mathrm{C}$ per day. The model of the collector to be used is the PA-E model each with an area of $2.17 \mathrm{~m}^{2}$, which analyzed according to the territory on which it is installed will give a certain amount of $\left[\mathrm{W} / \mathrm{m}^{2}\right]$ precisely in this case we must consider $700\left[\mathrm{~W} / \mathrm{m}^{2}\right]$.

In recent years, there has been a strong one-to-one correspondence between the city environment and Information and Communication Technology (ICT), which is a necessary condition for facing the challenges of sustainable development in a smart way at the local level. The theme of the Smart City is today pervasive and dominant compared to any other traditional urban theme. It represents a strategic priority of HORIZON 2020 and the different European regions borrow local guidelines on research and innovation. Sustainability should not be understood as a simple superposition of a technological code to the architectural project in a pure cladding perspective, the sustainable project is a set of good practices or architectural and urban composition rules, accompanied by the use of technology or the latest electronic discoveries supporting the complex urban functional mechanics.

In summary, a city or an "Ancient City" on an hill near the sea, as those analyzed, could be defined as "Smart" when investments in human and social capital, in traditional infrastructures, in mobility, in energy efficiency, in environmental sustainability, fuel sustainable economic development and a high quality of life, with a wise management of natural resources, through a method of participatory governance, which includes citizens in the definition and implementation of an integrated system of sustainable urban policies. Environmental management and monitoring is very important, as the understanding of its impact leads to an increase in regulation and activities aimed at reducing pollution. In this context we want to emphasize the new concept of "Smart Ancient City" and Magliano in Toscana is just one example, to highlight the importance of ancient villages and the desire to re-evaluate them, not only artistically and culturally but also from an energy point of view ,with a restructuring and "smart" devices enhancement, that can make them appreciable also at European level as resources and artistic-energetic heritage (Herity International as partner in the project for the future development). So we want to concentrate primarily on small cities and countries that have ideal characteristics and dimensions to implement a revolution that will come to invest the big cities, after obtaining the knowledge and developing the means for a radical change. The ancient city as well as being the most fascinating, can also become the most sustainable and the most intelligent: it has extracted everything it needed from the place. The technologies in use borrowed from local materials $(\mathrm{km}-$ Zero concept) and the shapes followed specific functional needs.

Promotion of sustainable lifestyles, support for local agriculture and trade in "km-Zero concept" products, green purchases, adherence to the Covenant of Mayors, compilation of a detailed and complete SEAP of individual cities and countries, sustainable architecture, dissemination of electric mobility and infrastructure for vehicle recharging, these are only a few possible ways towards the common goal of energy efficiency and not just of our society

\section{CONCLUSIONS AND FUTURE PERSPECTIVE}

The present study integrates new data with the existing one and literature concerning the new energy technologies applicable to "Smart Cities and Communities" and here defining and emphasizing the concept of "Smart Ancient Cities" and their use, with practical examples, aimed at encouraging efficiency energy, devices adaptable to walls and castles, including the mini-wing flags devices on the castle, the reduction of energy consumption and Green House Gases (GHGs), with the implementation of RESs, of low-enthalpy geothermal energy, the Biomass/Bio-methane plant, already available online (i.e., the Luigi Vivarelli's plant in Magliano in Toscana, is exemplary, not treated here only for a question of available space), which can be imitated throughout the country, and a critical historical analysis is underway, also analyzing the future implementations to be made, both in ICT and in infrastructure)

These "low carbon" energy production technologies, however, appear to be a key tool at national, European and global level to achieve the objectives of safeguarding the environment, jointed to the CCS powerful technologies to cut the GHGs (www.globalccsinstitue.org). the electricity production measurements were normalized with the variable Producible Low Carbon Energy Density (DEPLC) expressed in [MWhe/hectar/year] and for the DEPLC heat expressed in [MWht /hectar/year]. It has been analyzed and explained how the applications of energy redevelopment interventions in an ancient masonry village, such as Magliano in Toscana, where, moreover, anti-seismic structural redevelopment can be coupled with energy redevelopment, can represent a driving force for architectural, tourist and economic development, especially when, as in the case of Italy, primary energy resources are not present in sufficient quantities. An excellent starting point was identified in drafting documents such as the SEAP (critically summarily revised in this work with the results of many small municipalities analyzed) and the PEC, with the aim of providing a vision of the Energy Action Plan that we want to follow to achieve the European targets set for 2020 and later for 2030.

The study of the Municipality of Magliano in Toscana was examined, therefore as an example and reproducible considering also the starting difference of the experimental data typical of a small municipality on which energy balances were carried out, characterized by the integration of various technologies, including the typical photovoltaic one, to improve the energy production and efficiency of some public facilities.

The limits and improvements that can be applied to zeroemission transport, ICT, the increase in RESs, the biomass / bio-methane plant, a possible implementation of geothermal energy, including the critical analysis of the research permit in force in the municipality (medium-Enthalpy, still ongoing in Pareta), and an awareness of the individual that can promote a radical change, thanks to the incentive tools offered by local and regional governments.

Also the territory of Gran Canaria has some very interesting potentials, being characterized by consistent values of irradiance and a high wind resource, guaranteed by the intensity and constancy of the winds that lap the islands. In particular, on the island of El Hierro, excellent results have 
been achieved, guaranteeing the energy needs of the population in a $100 \%$ renewable way.

In conclusion, it is necessary, with a view to improving the distribution and methods of energy production, to know exactly the profile of the energy consumption of the cases in question, to make assessments regarding the local industrial plants, calculating in terms of normalization to the variable DEPLC in [MWhe/hectar/year] and the specific activities carried out / planned. A detailed diagnosis of the municipal energy requirement allows the client to verify the presence and the technical-economic feasibility of interventions that reduce energy consumption for the same energy produced in the space and time unit (DEPLC expressed in [MWhe/hectar /year]). It would be important to support the PAES with accurate technical-energy surveys that provide reliability in the acquisition of real data, traceability on the origin of energy and consumption, verifiability on proposed interventions to arrive at a correct rationalization of energy flows.

The transition to an economy with greater efficiency and sustainable in terms of energy and environment, should increase the spread of innovative technological solutions, improve the competitiveness of the industry and security of supply (adopting zero $\mathrm{km}$ production situations), reduce greenhouse gas emissions and primary energy consumption in the European Union; all reviving sustainable tourism, economic growth with the consequent creation of high quality of life jobs in various sectors".

\section{ACKNOWLEDGMENT}

The author thanks a lot Prof. Enzo Boschi and Prof. Ezio Masini to discuss daily the concepts expressed in this paper. Many thanks to the Magliano in Toscana Municipality Technical Office and the Major. Thank you to the Set Plan Energy Enlarged Board, Ministry MIUR for the ideas and discussion at this table for many years. A special thanks to Luigi Vivarelli and his enterprice staff.

\section{REFERENCES}

[1] EEA, EMEP/EEA air pollutant emission inventory guidebook. EEA, Copenhagen.” 2009.

[2] EU Strategic Energy Technology Plan WTO workshop on environmental technology dissemination November, 2012.

[3] ICLEI, "International Local Government GHG Emissions Analysis Protocol." http://archive.iclei.org/2009

[4] IPCC Guidelines for National Greenhouse Gas Inventories, Prepared by the National Greenhouse Gas Inventories Programme. Disponibile su http://www.ipccnggip.iges.or.ip/public/2006gl/index.html, 2006.

[5] Institute for Environment and Sustainability (Joint Research Centre). (2009). International Reference Life Cycle Data System (ILCD). http://lct.jrc.ec.europa.eu/eplca/deliverables. 2009

[6] Monforti, F., Huld, T., Bódis, K., Vitali, L., D'isidoro, M., Lacal-Arántegui, R. (2014). Assessing complementarity of wind and solar resources for energy production in Italy. A Monte Carlo approach. Renewable Energy, 63: 576586. https://doi.org/10.1016/j.renene.2013.10.028

[7] Patto dei Sindaci - per il clima e l'energia - Commitment
Document, 2016.

[8] Quattrocchi, F., Boschi, E., Spena, A., Buttinelli, M., Cantucci, B., Procesi, M. (2013). Synergic and conflicting issues in planning underground use to produce energy in densely populated countries, as Italy: geological storage of $\mathrm{CO}_{2}$, natural gas, geothermics and nuclear waste disposal. Applied Energy, 101: 393-412. https://doi.org/10.1016/j.apenergy.2012.04.028

[9] Procesi, M., Cantucci, B., Buttinelli, M., Armezzani, G., Quattrocchi, F., Boschi, E. (2013). Strategic use of the underground in an energy mix plan: Synergies among $\mathrm{CO}_{2}, \mathrm{CH}_{4}$ geological storage and geothermal energy. Latium Region case study (Central Italy). Applied Energy, 110: 104-131. https://doi.org/10.1016/j.apenergy.2013.03.071

[10] Buttinelli, M., Procesi, M., Cantucci, B., Quattrocchi, F., Boschi, E. (2011). The geo-database of caprock quality and deep saline aquifers distribution for geological storage of $\mathrm{CO}_{2}$ in Italy. Energy, 36(5): 2968-2983. https://doi.org/10.1016/j.energy.2011.02.041

[11] Bonanomi, M., De Flumeri, C., Lavagna, M. (2012). Edifici a consumo energetico zero. Orientamenti normativi, criteri progettuali ed esempi di Zero Energy e Zero Emissions buildings. Maggioli Editore.

[12] Kougias, I., Szabo, S., Monforti-Ferrario, F., Huld, T., Bodis, K. (2016). A methodology for optimization of the complementarity between small-hydropower plants and solar PV systems. Renewable Energy, 87: 1023-1030. https://doi.org/10.1016/j.renene.2015.09.073

[13] Geothermal EnergyAssociation (GEA) Eds. By: Alison Holm, Leslie Blodgett, Dan Jennejohn and Karl Gawell Alison Holm, Leslie Blodgett, Dan Jennejohn and Karl Gawell, "Geothermal Energy: International Market Update". 2010.

[14] McGrail, B.P. (2010). Low-temperature geothermal power: A welcome neighbor in densely populated region? 34-th Course of the International School of Geophysics "Densely populated settings: The challenge of siting geological facilities for deep geothermics. $\mathrm{CO}_{2}$ and natural gas storage, and radioactive waste disposalUnderground coexistence and synergies for a sound energy mix in the post-Kyoto era, Erice.

[15] Quattrocchi, F., Boschi, E. (2015). The Commissione Ichese case history as a poor geo-ethics and communication episode in the frame of the Nimby Syndrome and geopolicy weakeness. J. Earth Sci. Clim. Change, 6: 5. http://dx.doi.org/10.4172/2157-7617.S1.0. 2015

[16] Arrizabalaga, I., De Gregorio, M., De Santiago, C., García de la Noceda, C., Pérez, P., Urchueguía, J. (2017). Geothermal Energy Use, Country Update for Spain. Geophysical Research Abstracts, 19: EGU2017-7471.

[17] Arrizabalaga I., De Gregorio, M., De Santiago, C., García de la Noceda, C., Pérez, P., Urchueguía, J. (2019). Geothermal Energy Use, Country Update for Spain. Proceedings European Geothermal Congress 2019 Den Haag, The Netherlands, 11-14.

[18] Rodríguez, F., Pérez, N.M., Padrón, E., Melián, G., Hernández, P.A., Asensio-Ramos, M., Dionis, S., López, G., Marrero, R., Padilla, G.D., Barrancos, J., Barrancos, J. (2015). Diffuse helium and hydrogen degassing to reveal hidden geothermal resources in oceanic volcanic islands: The Canarian archipelago case study. Surveys in Geophysics, 36(3): 351-369. 
http://dx.doi.org/10.1007/s10712-015-9320-8

[19] Rodríguez, F., Pérez, N.M., Padrón, E., Melián, G., PiñaVaras, P., Dionis, S., Barrancosa, J., Padillaa, G, D., Hernández, P.A., Marrero, R., Ledo, J.J., Bellmunt, F., Queralt, P., Marcuello, A., Hidalgo, R. (2015). Surface geochemical and geophysical studies for geothermal exploration at the southern volcanic rift zone of Tenerife, Canary Islands, Spain. Geothermics, 55: 195-206. https://doi.org/10.1016/j.geothermics.2015.02.007 